\title{
Phytoprotection
}

\section{Index des auteurs, volume 86 Author Index, volume 86}

Volume 86, numéro 3, décembre 2005

URI : https://id.erudit.org/iderudit/013078ar

DOI : https://doi.org/10.7202/013078ar

Aller au sommaire du numéro

\section{Éditeur(s)}

Société de protection des plantes du Québec (SPPQ)

ISSN

0031-9511 (imprimé)

1710-1603 (numérique)

Découvrir la revue

Citer ce document

(2005). Index des auteurs, volume 86. Phytoprotection, 86(3), 201-202.

https://doi.org/10.7202/013078ar d'utilisation que vous pouvez consulter en ligne.

https://apropos.erudit.org/fr/usagers/politique-dutilisation/ 
Index des auteurs, volume 86

Author Index, volume 86

A-C

Abawi, G.S.

Adamcíková, K.

Ahne, R.

Anderson, $\mathrm{T}$.

Antoun, $\mathrm{H}$.

Bahi, W.

Baranski, R.

Barasubiye, $\mathrm{T}$.

Béasse, $\mathrm{C}$.

Beaudry, N.

Beaulieu, C.

Bélair, G.

Bélanger, $B$.

Bélanger, $\mathrm{M}$.

Bélanger, R.R.

Benoit, D.L.

Bernier, L.

Bilodeau, G.

Boivin, M.

Boland, G.J.

Bourassa, A.

Bourgeois, G.

Bourget, N.

Breton, D.

Breuil, C.

Briard, M.

Brisson, J.D.

Britz, S.J.

Brodeur, L.

Bussières, $\mathrm{P}$.

Cadieux, M.

Caldwell, C.D.

Caron, J.

Charest, J.

Charles, M.T.

Cherif, M.

Chevrier, N.

Choo, T.M.

Choquette, D.

Ciotola, M.

Clear, R.M.

Clevidence, B.A.

Collin, J.

Comeau, A.

Couture, L.

\section{D-K}

Daigle, N.

Dalpé, Y.

Dangi, O.P.

Dauphinais, N.

Delalande, D.

Desbiens, M.-C.

Dionne, J.

Dizengremel, P.

Dostaler, D.

Driedger, D.

Duchaine, C.

Ehrig, F.

Etienne, M.

Falk, D.E.

Farrar, J.

Foster, A.J.

Fournier, Y.

Gaucher, C.

Gençer, L.

Gladysz, K.

Gorrias, F.

Goyette, B.

Gravel, V.

Grzebelus, D.

Grzebelus, E.

Gugino, B.K.

Hamelin, R.C.

Hogue, R.

Hooper, C.

Hovius, M.H.Y

Janvier, C.

Jarraya, A.

Joy, P.

Juhásová, G.

Kegode, G.O.

Kharrat, S.

Kielkowska, A.

Krämer, R.
75

53,74

195

195

145

76

72

7

154

141

72

142

73

73

137

138

135, 195

7

133

142

135

137

74,81

142

142

138

72

75

31

140

146

25

139

19

125

25

142

145 


\section{L-M}

Lada, R.

Laflamme, G.

Landry, J.A.

Langevin, F.

Lapen, D.

Lapointe, M.

Laverdière, L.

Le Clerc, V.

Légère, $A$.

Lemay, I.

Lemieux, C.

Lévesque, C.A.

Lévesque, $M$.

Ludwig, J.W.

Ma, B.L.

MacDonald, T.

Maignien, G.

Majeau, J.-A.

Markarian, N.R

Martin, R.A.

Martinez, C.

Mauffette, Y.

Mazzola, M.

McDonald, M.R.

McGiffen, M.

McKeown, A.W.

McLaughlin, N.

Michaud, D.

Montford, F.

Morin, C.

\section{N-R}

Neeser, C.

Nelson, E.A.

Nothnagel, T.

Novotny, J.A.

Ouellette, G.B.

Pagé, D.

Panneton, B.

Parent, S.

Pawelec, A.

Peters, R.D.

Philion, V.

Plouffe, D.

Plourde, K.

Potter, J.

Pouleur, S.

Prunier, M.

Quilitzsch, R.

Rabenstein, F.

Riga, E.

Rioux, D.

Rioux, S.

Rivera, M.

Robin, C.

Rogers, P.M

Roussel, D.

Roy, G.

Roy, $\mathrm{M}$.

\section{S-Y}

139, 144

$37,75,78$

146

$43,74,75$

78

71

79

139

76

137

76

$71,72,78$

43,74

138

78, 189

79

146

77

146

73

74,76

7

77

138, 139, 140, 147

144

147

78

93, 107

$136,140,145$

76

141

125

$141,142,145$

144

157, 175

72

76

77

136

143

77

136

77

31

77

136

142

145

31

$3,4,78,86,155,175$

71,75

143

19

143

137

76

61,78
Sanderson, K.

143,144

Savard, M.

Schrader, O.

Seifert, K.A.

Seven, $S$.

Siel, A.

Simard, L.

Simard, M.

Simon, P.W.

Sparry, E.

Steinberg, C.

Stevensen, W.R.

Stiles, A.

Straka, P.

Suffert, F.

Tambong, J.T.

Tanguay, $\mathrm{P}$.

Tanumihardjo, S.A.

Tenuta, A.

Toussaint, V.

Trudel, R.

Tweddell, R.J.

Ulrich, D.

Vander Kooi, K.

Venne, J.

Vigier, B.J.

Vigneault, $\mathrm{C}$.

Villeneuve, $\mathrm{F}$.

Welacky, T.W.

Westerveld, S.M.

Wyand, S.

Xue, A.G.

Yang, D.-O.
73

142

71

133

139

72

$78,157,175$

$139,143,144$

73

146

143

144

$141,142,145$

$89,140,145$

78

76

144

71

79,146

5,87

74

145

139,140

79

73, 189

137,146

146

71

147

144

189

76 